\title{
Influence of insolation and ambient temperature on operation of digital voltage transformers in Russia
}

\author{
Elena Gotovkina ${ }^{1}$, Vladimir Tyutikov ${ }^{2}$, Nikolay Smirnov ${ }^{2,}$, , Vladimir Lebedev ${ }^{1}$ and Evgeniy \\ Bushuev $^{2}$ \\ ${ }^{1}$ Ivanovo State Power Engineering University, Electric Power Engineering Department, 153003 \\ Ivanovo, Russia \\ ${ }^{2}$ Ivanovo State Power Engineering University, Heat Power Engineering Department, 153003 Ivanovo, \\ Russia
}

\begin{abstract}
The present study is devoted to questions connected with influence of solar radiation and high values of ambient air temperatures on work of digital voltage transformers. The developed designs of digital voltage transformers are included in smart grid system of technical and commercial metering of electric energy consumption. The analysis of the unfavorable conditions for work of digital voltage transformers for the conditions of Russia in summer is carried out. The results of mathematical simulation for thermal state of transformers, obtained with the help of COMSOL Multiphysics program based on the finite element method, are presented. Experimental research regarding the thermal field of resistive voltage divider transformer was conducted on a verified mathematical model in order to determine the position of resistive elements where their self-heating is minimal.
\end{abstract}

\section{Introduction}

As a part of the creation of electronic measuring instruments for Smart Grids it is vital to develop a high-voltage measuring transformer based on a resistive voltage divider [1]. The transformer model based on a resistive voltage divider is shown in Figure 1.

The actual task is to diagnose the developed transformer designs, which will identify weaknesses in their functioning and increase the reliability of the proposed equipment. Particular attention should be paid to issues related to the operation of measuring transformers in the real climatic conditions of Russia. In the summer months, with high outside air temperatures and high insolation, the probability of overheating of transformers operating with above nominal voltage increases. Consequently, it becomes necessary to model the operation of the transformer under these unfavourable conditions.

\footnotetext{
*Corresponding author: nsmirnov@,bk.ru
} 


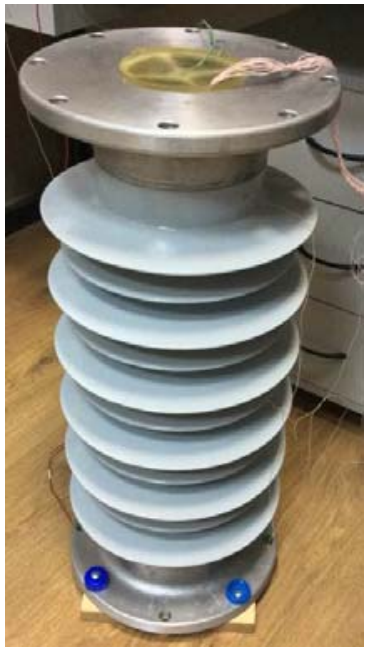

(a)

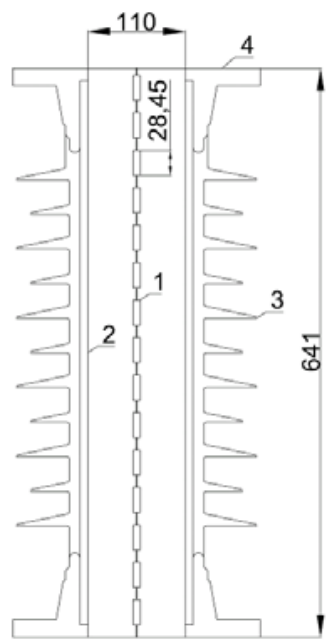

(b)

Fig. 1. Resistive voltage divider transformer: $\mathrm{a}$ - experimental model photograph; $\mathrm{b}$ - drawing; 1 resistive elements; 2 - glass textolite tube; 3 - silicone cover; 4 - flange.

\section{Placement of digital voltage transformers}

Digital voltage transformers included in the system of technical and commercial metering of electrical energy consumption can be located both in a closed switchgear (in a transformer substation) and in the open air.

Digital transformers are devices that actively generate thermal energy, therefore, usually, the heating system is not used in buildings with transformers. In premises with digital transformers it is envisaged the use of forced-air and exhaust ventilation to maintain the necessary temperature around this measuring device. In the premises of substations with large heat dissipation from the measuring device in summer time, mechanical air supply to the lower part of the premises is usually organized with the help of air fans. There are exhaust chutes in the upper part of the premises.

In the case of measuring transformer location in the open air, the most unfavorable working conditions of this equipment are added in summer, in cloudless weather, in a calm, when there are significant heat inputs to the surface of the transformer from the Sun. In windless weather $(v \rightarrow 0 \mathrm{~m} / \mathrm{s})$ there are also additional difficulties with the organization of heat removal from transformer surface due to low convective component of heat transfer.

\section{Analysis of changes in air temperature and insolation for summer conditions in Russia}

It is known that insolation has a negative impact on the work of electrical energy-saturated equipment [2], especially in countries with hot climates [3, 4].

An analysis of changes in air temperature and solar activity in summer was made, and the time of their greatest total value was determined. So, according to the data of Poghosyan H.P. [5], the maximum value of air temperature in clear weather is fixed in the afternoon from 13 to 16 hours (Figure 2), when the soil surface and the objects located on it are sufficiently heated from the Sun. For this time of day, the greatest heat fluxes of solar radiation fall on the surface facing the west (Figure 3, item b), and these values are greater than the maximum insolation on the surface facing south (Figure 3, item a). 


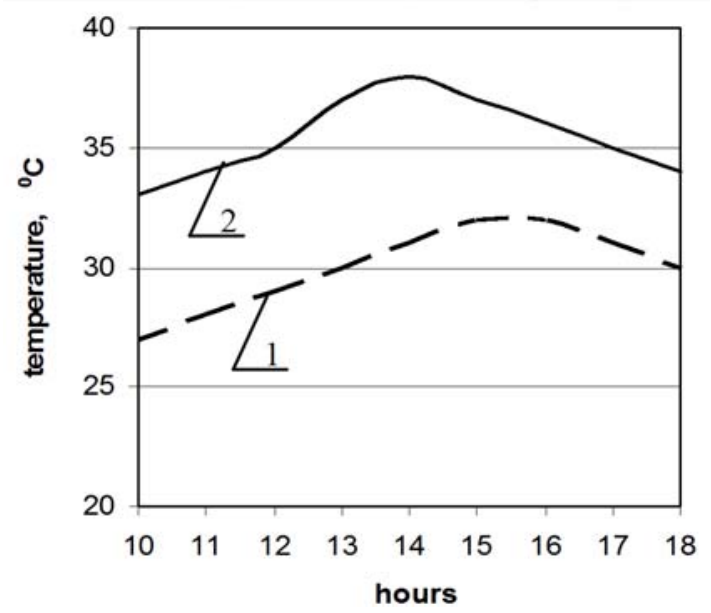

Fig. 2. Daily variation of air temperature in Sochi (1) and Dushanbe (2).

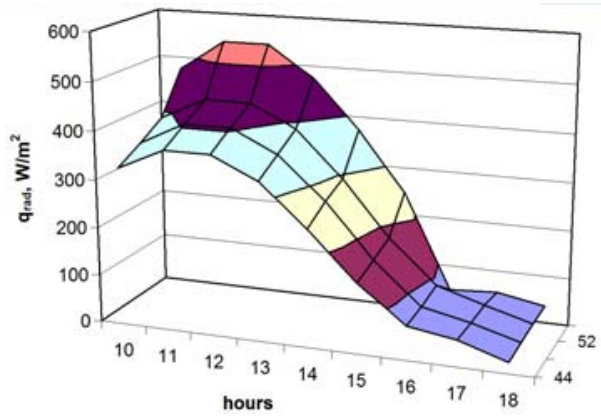

(a)

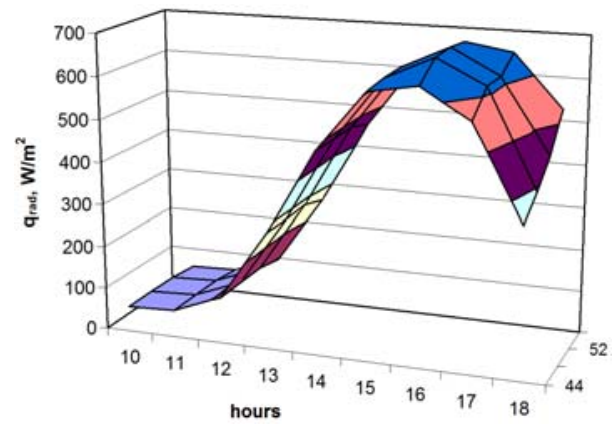

(b)

Fig. 3. Surface flux density of total solar radiation in July $q_{\mathrm{rad}}, \mathrm{W} / \mathrm{m}^{2}$, depending on the time of day and the location of the object (degrees north latitude) for the southern (a) and western (b) orientation of the vertical surface. It is created on the basis of data [6].

Consequently, from the point of view of heat exchange with the environment the most unfavourable conditions will be for the surfaces of the digital transformer facing west, during the time from 14 to 16 hours.

It was interesting to find out what are the maximum ambient air temperatures recorded in the territory of the Russian Federation in various regions.

The average of the absolute maximum air temperature is calculated as the multi-year average of the absolute maximum temperature for each individual year. This characteristic is a good indicator of the highest temperatures observed annually in one of the summer months (usually in June or July). Isotherms have a predominantly latitudinal direction, with the exception of the coasts of the seas of the Pacific Ocean. From Moscow to Yakutia at north latitudes in the range $50^{\circ} \ldots 60^{\circ}$ the average of the absolute maximums is $+32{ }^{\circ} \mathrm{C}$. The highest values of the average absolute maximum air temperature are observed in the south of the European part of Russia: the Stavropol Upland, the Republic of Kalmykia, the Lower Volga, and also in the Krasnodar Territory and the North Caucasus. Here, the maximum air temperature can rise to $+36^{\circ} \ldots+38^{\circ} \mathrm{C}$ and above almost every year. 


\section{Simulating thermal state of transformer in COMSOL Multiphysics}

The heat exchange of the digital voltage transformer with the environment was simulated when the solar radiation and internal heat from the resistors were applied to it (Figure 4).

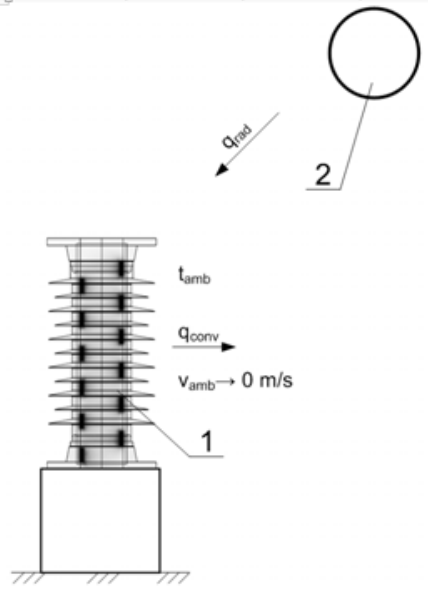

(a)

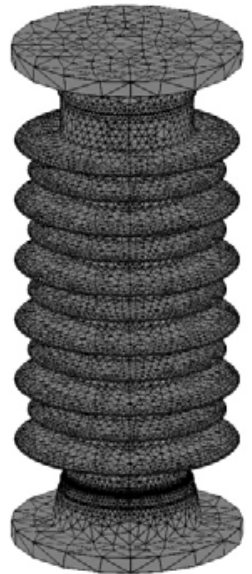

(b)

Fig. 4. Diagram of heat exchange model (a) of digital transformer with the surrounding environment in cloudless weather, as well as variant of splitting the transformer model into finite elements (b): 1 transformer; 2 - Sun.

The use of solid state insulation material creates additional heat resistance, hindering heat removal from resistive elements [1]. Warming of resistive elements may lead to changes in their active resistance and therefore reduced accuracy in voltage measurement using a resistive divider. Increased resistance leads to reduced self-heating of resistive elements and thus smaller errors.

To limit maximum temperatures as required by guidelines for heat testing and use of resistive elements, we selected a maximum positive temperature value for resistive element surfaces of $100^{\circ} \mathrm{C}$.

The applied numerical method of solving heat transfer is the finite elements method, using COMSOL Multiphysics software package. The developed finite element grid of the three-dimensional transformer model includes more than 150,000 tetrahedra (Figure 4).

A digital voltage transformer was placed in the center of the model (Figure 4). The rated measurable voltage was set. The air temperature was taken as $40^{\circ} \mathrm{C}$, based on the above discussion. The position of the Sun was simulated on the west side to the transformer, with the sun rays angle on the surface of the transformer and the intensity of insolation being set for 16 hours. The thermal radiation flux from the Sun was simulated within $600 \mathrm{~W} / \mathrm{m}^{2}$, initially measuring it on the surface of the transformer without taking into account the internal heat dissipation from the resistors. Coefficients of convective heat transfer were determined from the data of a physical experiment conducted in the study of convective heat transfer between the edges of the transformer and the surrounding air [1].

Experimental research regarding the thermal field of resistive voltage divider transformer was conducted on a verified mathematical model in order to determine the position of resistive elements where their self-heating is minimal. The following variants of the arrangement of resistors were accepted: axial, boundary and spiral. 


\section{Results of heat transfer modelling between operating transformer and surrounding environment under intense insolation}

Based on the simulation results, it can be stated that the presence of insolation significantly increases the temperature on the surface of the digital voltage transformer. So, with solar radiation on a digital transformer with a boundary position of resistors (Figure 5), the maximum temperature on the surface increases from 44 (in the control) to $54^{\circ} \mathrm{C}$ (in case of insolation). In the absence of insolation, the maximum temperature on the surface of the transformer is fixed in the area of the resistors, while on the surface of the ribs the temperature does not exceed $42^{\circ} \mathrm{C}$. In case of insolation, the maximum temperature is in the zone of the upper ribs and flange. It should be noted that the geometry of the ribs protects the resistors from direct solar radiation.

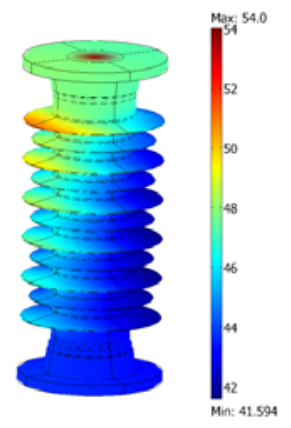

(a)

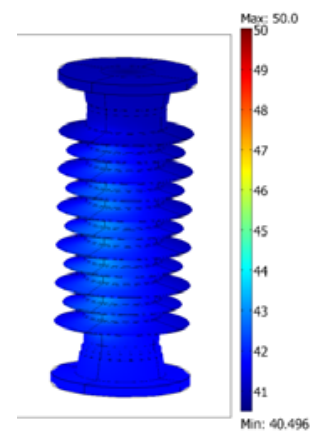

(b)

Fig. 5. Temperature fields on the surface of the transformer with a boundary position of resistors in the presence (a) and absence (b) of insolation.

The results of heat transfer simulating of the transformer with the environment in the absence of insolation are presented in Figure 6.

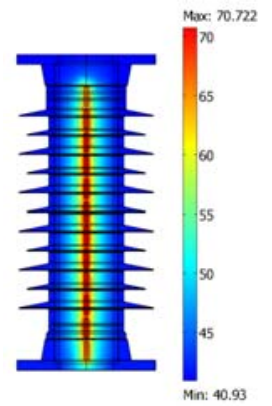

(a)

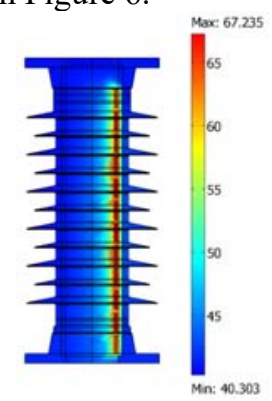

(b)

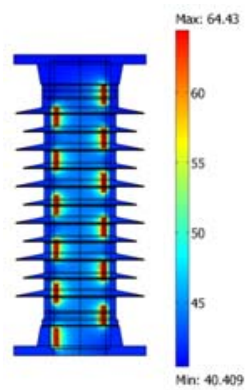

(c)

Fig. 6. The comparison of thermal fields of resistive voltage divider transformer with axial (a), boundary (b) and spiral (c) position of resistive elements in the absence of insolation.

It should be noted, that in the case of axial position of resistive elements, the temperature on the surface of the resistors will be $70.7^{\circ} \mathrm{C}$, with the boundary position $+67.2^{\circ} \mathrm{C}$, with a spiral position $-+64.2^{\circ} \mathrm{C}$. Therefore, the resistive divider moving to inner wall of the insulator allows decreasing resistive elements temperature by $3.5^{\circ} \mathrm{C}$, and spiral position of resistive elements additionally reduces the temperature by $3.0^{\circ} \mathrm{C}$. 
Figure 7 shows the results of the heat transfer modelling of the transformer with the surrounding environment in the case of insolation. It should be noted that the insolation warms up the internal volume of the transformer, especially the upper flange and ribs, oriented to the western location. Temperature on the surface of the resistors will be $74{ }^{\circ} \mathrm{C}$ in the case of axial position of resistive elements, with the boundary position $-+72^{\circ} \mathrm{C}$, with a spiral position $-+70^{\circ} \mathrm{C}$.

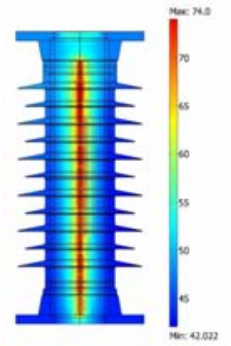

(a)

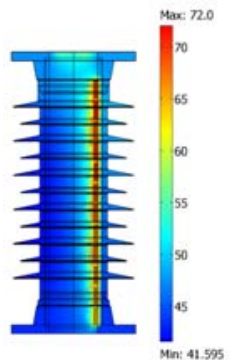

(b)

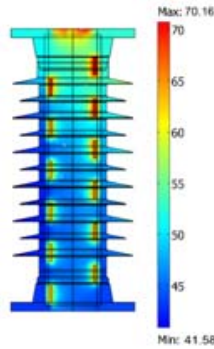

(c)

Fig. 7. The comparison of thermal fields of resistive voltage divider transformer with axial (a), boundary (b) and spiral (c) position of resistive elements at surface insolation.

We can also conclude that if the resistive elements are placed in a spiral position, the temperature on their surfaces is reduced. Insolation causes an increase in the temperature of the resistive element in the axial position by $3.3^{\circ} \mathrm{C}$ (from 70.7 to $74^{\circ} \mathrm{C}$, respectively), with the boundary position - by $4.8^{\circ} \mathrm{C}$ (from 67.2 to $72^{\circ} \mathrm{C}$, respectively), with a spiral by $5.8{ }^{\circ} \mathrm{C}$ (from 64.2 to $70{ }^{\circ} \mathrm{C}$, respectively).

\section{Conclusion}

The most difficult thermal state of a digital transformer located in the southern Russia on open air is in the second half of summer day, and the surfaces facing the west are particularly exposed to thermal action from the sun. The spiral position of resistive elements is the most expedient from the point of view of effective heat removal.

This research was conducted with financial support from the Ministry of Education and Science of the Russian Federation at Ivanovo State Power Engineering University within the framework of a federal target program "Research and Development in Priority Areas of Developing the Russian Scientific and Technological Complex in 2014-2020" concerning "A Multifunctional System based on Digital Current and Voltage Transformers for a Digital Substation" (Agreement No. 14.577.21.0276 on Granting Subsidies, dated 26 September 2017, Unique Identifier for Applied Scientific Research (Projects) RFMEFI57717X0276).

\section{References}

1. V.D. Lebedev, A.A. Yablokov, IOP Conf. Ser.: MSE., 177 (2017)

2. K. Bakirci, Energy, 34 (2009)

3. F.Q. Al-Enezi, J.K. Sykulski, N.A. Ahmed, Energy Procedia, 12 (2011)

4. J. Almorox, C.Hontoria, Energy Convers. Manage, 45 (2004)

5. H.P. Pogosyan, The air shell of the earth (Gidro, Leningrad, 1962)

6. V.K. Pyzhov, Energy supply systems for life and human activities (ISPEU, Ivanovo, 2014) 